\title{
REMUNERAÇÃO DOS GESTORES, PÚBLICO ALVO E CONFLITOS DE INTERESSE EM FUNDOS DE AÇÕES NO BRASIL
}

\author{
Flávio Cysneiros Sanematsu *
}

\begin{abstract}
Resumo
Este trabalho analisa o comportamento dos fundos de investimento em ações (FIAs) nos encerramentos de semestre. Os resultados indicam que os FIAs apresentam retornos anormais positivos no encerramento do semestre, acompanhados de retorno anormal negativo no dia seguinte ao encerramento do semestre. Os retornos anormais estão associados a uma baixa capacidade de monitoramento do comportamento do gestor. Fundos destinados ao público geral são mais propensos a apresentarem retornos anormais nessas datas. As evidências da associação dos retornos anormais com a remuneração atrelada ao desempenho não foram tão claras quanto a separação pela clientela dos fundos.
\end{abstract}

Palavras-chave: Problemas de Agência; Retornos Anormais; Fundos de Investimento.

\begin{abstract}
This paper is aimed at the investigation of the behavior of equity mutual funds at semester-ends. Results indicate that Brazilian equity funds present positive abnormal returns on the last trading day of semesters, followed by negative abnormal returns at the subsequent day. Abnormal returns are associated with poor monitoring skill of managers' behavior. Retail funds are more likely to present abnormal returns at semester-ends. Evidence of abnormal returns associated with performance-based compensation is not as strong as the one provided by the distinction of funds' clientele.
\end{abstract}

Keywords: Agency Problems; Abnormal Returns; Mutual Funds.

JEL classification: G14, G23

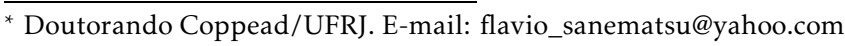




\section{Introdução}

Um dos potenciais problemas na gestão profissional de carteiras é a existência do problema de agente e principal. Nesse caso, o agente é o gestor do fundo e o conflito que surge é a possibilidade de ele adotar uma estratégia que otimize sua riqueza em vez de buscar a maximização da riqueza de seus investidores. Para otimizar sua riqueza, o gestor pode tentar maximizar a taxa de performance cobrada dos investidores ou então buscar atrair novos fluxos de capitais ao reportar desempenho superior por meio da manipulação da cotação de alguns ativos que compõem sua carteira. Os investidores acabam não obtendo do gestor uma maximização do retorno pois (1) para manipular o preço das ações, ainda que por um curto instante de tempo, o gestor incorre em custos que serão arcados pelos investidores; (2) a taxa de performance cobrada representa uma transferência de riqueza permanente dos investidores para o gestor; e (3) a carteira pode estar sendo formada de maneira que se possam incorporar ativos que facilitem a manipulação dos preços em detrimento de ativos que poderiam ter uma relação de risco e retorno mais interessante para o problema de maximização do investidor.

Para verificar se esse conflito de interesses entre gestores e investidores existe, consideramos para a análise o caso dos fundos mútuos de ações brasileiros, também chamados de Fundos de Investimento em Ações (FIAs). Especificamente, a pesquisa investiga se os gestores atuam de forma a influenciar o preço dos ativos que compõem as carteiras de seus fundos. Essa influência no preço dos ativos, ainda que temporária, teria como objetivo inflacionar o valor da cota. Essa inflação no valor da cota permitiria ao fundo reportar um desempenho superior, o que poderia tornar o fundo mais atrativo para a captação de novos recursos. Caso o fundo cobre taxa de performance de seus investidores, a inflação no valor da cota propiciaria ao gestor do fundo uma remuneração maior, uma vez que o cálculo do pagamento da taxa de performance leva em consideração o valor da cota.

Como a estratégia de tentar influenciar a cotação de um ativo implica custos e aumento de risco, os gestores dos fundos devem recorrer a ela apenas em momentos-chave. No Brasil, as taxas de performance dos fundos costumam ser cobradas semestralmente, usualmente adotando como datas para cobrança desse encargo os encerramentos dos semestres civis. Além disso, é praxe utilizar a rentabilidade do ano anterior como medida de performance perante os investidores dos fundos e potenciais clientes. Assim, as datas que consideramos importantes e nas quais concentraremos nosso estudo são os encerramentos dos semestres civis para os fundos que não cobram taxa de performance ou para aqueles em que ela é cobrada com base nessas datas; para os fundos em que a taxa de performance incide com base em outras datas, estas são adotadas como as relevantes para nossa análise. Essas datas serão denominadas como períodos de encerramento.

Dessa forma, a pesquisa vai investigar se os FIAs apresentam retornos anormais nas datas de encerramento de período para tentar encontrar evidências de que os gestores podem estar atuando de maneira a alterar os preços dos ativos, ainda que por um curto instante de tempo, de modo a apresentar um melhor desempenho ou para gerar uma maior taxa de performance.

Uma outra alternativa seria examinar as composições diárias das carteiras nos dias próximos aos períodos de encerramento. Com isso, seria possível verificar como o gestor atua para modificar a carteira nessas datas. Entretanto, 
esse teste não pode ser feito pois apenas a carteira do último dia do mês dos fundos é disponibilizada. Dessa forma, não é possível acompanhar as alterações feitas pelo gestor nos dias próximos ao encerramento do mês e nos dias subsequentes.

Para tentar diferenciar se o desvio de comportamento dos gestores se deve à tentativa de obter uma maior remuneração por meio da taxa de performance ou então à tentativa de reportar desempenho superior, iremos analisar se existem diferenças entre os retornos no período de encerramento dos fundos que cobram taxa de performance dos FIAs que não a cobram. Caso os fundos em que a taxa de performance seja cobrada apresentem uma maior incidência de retornos anormais nessa data, temos um indício de que o incentivo gerado pelo pagamento da taxa de performance ao gestor pode levá-lo a agir de modo desalinhado ao interesse dos cotistas de seu fundo.

Outra comparação que faremos será entre os fundos restritos a investidores qualificados frente aos fundos abertos ao público geral. Nesse caso, queremos investigar se os gestores atuam de maneira diferente, dependendo da clientela para a qual seu FIA está voltado. Investidores qualificados têm, em princípio, uma maior capacidade de monitorar a atuação do gestor do que o público geral. Com uma maior capacidade de monitoramento, os investidores qualificados podem enxergar a prática de inflacionar os preços dos encerramentos de período como prejudicial aos seus interesses, fazendo com que o gestor do fundo não recorra a esse artifício quando sua clientela é formada por investidores qualificados.

Além disso, as diferentes clientelas podem responder de modo diferente aos resultados apresentados pelo gestor de seus recursos. Os pequenos investidores que estiverem insatisfeitos com o desempenho de um gestor podem resgatar seus recursos de um fundo e aplicá-los em um outro fundo. Os investidores qualificados insatisfeitos com o desempenho de um gestor têm maior capacidade de se mobilizar para contratar um novo gestor para seus recursos. A possibilidade de ser substituído por um outro gestor nos fundos destinados aos investidores qualificados pode atuar para inibir a ocorrência de retornos anormais nos fundos dessa clientela no encerramento dos períodos com o objetivo de reportar melhores desempenhos ou aumentar a taxa de performance a ser paga ao gestor.

Para aprofundar a investigação entre as diferentes clientelas dos gestores, iremos analisar se existe diferença entre os retornos anormais registrados pelos fundos restritos a investidores qualificados que cobram taxa de performance e os FIAs destinados ao público geral que também cobram esse encargo. Os fundos destinados ao público geral estão sujeitos a regras mais rígidas para a cobrança de taxa de performance quando comparados aos fundos restritos aos investidores qualificados. ${ }^{1}$

Essa diferença na regulamentação da taxa de performance pode fazer com que os FIAs voltados aos investidores qualificados e que cobram a taxa de per-

\footnotetext{
${ }^{1}$ De acordo com a Instrução CVM 409 de agosto de 2004, em seu artigo 62, § $1^{\circ}$ determina que a cobrança da taxa de performance deve atender aos seguintes critérios: I — vinculação a um parâmetro de referência compatível com a política de investimento do fundo e com os títulos que efetivamente a componham; II — vedação da vinculação da taxa de performance a percentuais inferiores a $100 \%$ do parâmetro de referência; III - cobrança por período, no mínimo, semestral; e IV - cobrança após a dedução de todas as despesas, inclusive da taxa de administração. O $\S 2^{\circ}$ do art. 62 veda a cobrança de taxa de performance quando o valor da cota do fundo for inferior ao seu valor por ocasião da última cobrança efetuada (high-water mark). O $\S 4^{\circ}$ do art. 62 dispensa os fundos destinados exclusivamente a investidores qualificados de observar o disposto neste artigo.
} 
formance apresentem uma maior proporção de retornos anormais nos encerramentos de período do que os fundos que também têm taxa de performance mas sejam voltados ao público geral. Caso isso ocorra, a regulamentação menos restritiva aplicada aos fundos destinados exclusivamente a investidores qualificados permite aos gestores obterem uma maior taxa de performance por meio dos retornos anormais nos períodos de encerramento. Por outro lado, caso os retornos anormais estejam menos presentes nos fundos voltados aos investidores qualificados, a regulamentação menos restritiva para esse tipo de clientela não representa uma oportunidade para o gestor do fundo atuar de maneira oportunista.

Caso se encontrem indícios de que os FIAs apresentam retornos anormais nos períodos de encerramento, a etapa subsequente vai investigar se uma mudança de regra na marcação a mercado dos FIAs pode ter criado novos incentivos para o comportamento do gestor se desviar do objetivo desejado pelos investidores. Em maio de 2008 a marcação a mercado dos FIAs foi alterada, adotando-se o preço de fechamento em lugar do preço médio ponderado do dia. ${ }^{2}$ Esse novo critério de precificação dos fundos pode ser propício a práticas de manipulação de preço dos ativos por parte dos gestores dos FIAs com vistas a inflar o valor das cotas dos FIAs.

Uma vez que o preço a ser adotado para precificar o valor dos ativos nos FIAs passou a ser o preço de fechamento, determinado como o preço do leilão de fechamento do pregão ou então pelo último negócio executado no caso das ações menos líquidas, e não mais pelo preço médio do dia ponderado pelo volume financeiro dos negócios, pode-se ter criado um incentivo para que os gestores dos FIAs procurem influenciar o preço de fechamento das ações de forma a inflacionar o valor das cotas dos fundos.

O incentivo se dá pelo menor custo de alterar a cotação de fechamento de um papel quando comparado ao custo de tentar mudar sua cotação média. Em princípio, essa tentativa de alterar o preço não se justifica para ações de alta liquidez. Vendas a descoberto costumam ser feitas em maior quantidade em ativos que apresentam liquidez mais alta, de modo que as tentativas de inflacionar o preço de um ativo podem ser neutralizadas por vendedores a descoberto. Em ações de liquidez média ou baixa a participação de vendedores a descoberto é baixa, ou até nula no caso de ações de liquidez muito baixa, o que pode propiciar a manipulação para cima do preço desse ativo de liquidez reduzida. Por conta disso, as ações passíveis de estratégias que busquem alterar sua cotação de fechamento no dia de encerramento do período são aquelas que apresentam liquidez média ou baixa.

A mudança na marcação a mercado dos FIAs para o preço de fechamento permite analisar se a atuação dos gestores nos encerramentos de período se alterou. Caso os retornos anormais tenham se tornado mais frequentes e com maior magnitude após a mudança, ela pode ter deixado os investidores em pior situação, uma vez que os custos da inflação do valor das cotas são arcados pelos investidores dos fundos.

Portanto, a pesquisa tem como objetivo investigar se os retornos anormais nos encerramentos de período estão associados a potenciais problemas de agência. Os retornos anormais podem ser gerados pela tentativa por parte do gestor tanto de reportar desempenhos superiores, o que poderia aumentar

\footnotetext{
${ }^{2}$ Instrução CVM 465 de 20 de fevereiro de 2008, Arts. $3^{\circ}, 4^{\circ}$ e $5^{\circ}$, sendo que a mudança para marcação pelo preço de fechamento deveria ser adotada em maio de 2008.
} 
o apelo do fundo para a captação de novos recursos, quanto de ele obter uma maior remuneração por meio de uma taxa de performance computada com base em um valor de cota inflacionado.

\section{Revisão da literatura}

Carhart et al. (2002) já haviam detectado que gestores de fundos mútuos de ações nos EUA executam mais negócios nos últimos minutos do pregão, tanto dos encerramentos de trimestre quanto do ano, de forma a influenciar o preço de fechamento nessas datas, uma vez que são em relação a elas que os gestores precisam divulgar seus resultados e apropriar a remuneração pelo seu desempenho, caso se aplique. De acordo com os autores, os fundos mútuos de ações dos EUA apresentam retornos descontados do índice de referência (S\&P500) anormalmente altos e econômica e estatisticamente significantes no dia de encerramento dos trimestres e do ano. Além disso, os retornos no dia seguinte a essas datas são anormalmente baixos, caracterizando a reversão da inflação do retorno.

Para investigar se existem indícios de retornos anormais altos no último dia do trimestre e/ou do ano seguidos por um retorno anormalmente baixo no dia seguinte, Carhart et al. (2002) constroem carteiras dos fundos mútuos de ações dos EUA com base na classificação definida em Carhart (1997), e também por uma carteira que agrega todos os fundos mútuos de ações estadunidenses. Para a construção dessas carteiras, a ponderação utilizada foi dar o mesmo peso para cada um dos fundos, independente do tamanho. Após subtraírem de cada uma dessas carteiras o retorno do S\&P 500, os autores chegam aos retornos anormais de cada uma delas. Se os valores das carteiras forem inflados nos encerramentos de mês, trimestre, e/ou ano, retornos anormais positivos e estatisticamente significantes devem surgir no dia do encerramento dos períodos ( $M E N D, Q E N D, Y E N D$, respectivamente) e retornos anormais negativos devem aparecer no dia seguinte ao encerramento dos períodos ( $M B E G, Q B E G, Y B E G$, respectivamente). A partir da estimativa do modelo de Mínimos Quadrados Ordinários (MQO) em que a variável dependente é o retorno anormal da carteira $i$ no dia $t, R_{i, t}$, e as variáveis explicativas são binárias de encerramento do período e do dia de negociação seguinte ao encerramento, além de uma constante:

$$
\begin{aligned}
R_{i, t}= & b_{i, 0}+b_{i, 1} Y E N D_{t}+b_{i, 2} Y B E G_{t}+b_{i, 3} Q E N D_{t}+ \\
& b_{i, 4} Q B E G_{t}+b_{i, 5} M E N D_{t}+b_{i, 6} M B E G_{t}+\epsilon_{i, t}
\end{aligned}
$$

Os resultados de Carhart et al. (2002) indicam que as carteiras dos fundos mútuos apresentam inflação dos valores de encerramento de trimestre e de ano, mas nos encerramentos de mês esse efeito é pequeno ou inexistente. Para verificar se a prática da inflação nos valores das cotas está disseminada entre os fundos mútuos, a variável dependente da Equação 1 é substituída pela proporção dos fundos que apresentaram retorno anormal positivo no instante $t$. A proporção de fundos com retorno anormal positivo no encerramento do ano é maior do que a mesma proporção nos encerramentos dos outros trimestres, indicando que a prática de inflacionar o valor das cotas nos encerramentos dos períodos, em especial no final do ano, está presente em muitos fundos mútuos de ações dos EUA. 
Gallagher et al. (2009) encontram evidências de que gestores de fundos institucionais na Austrália costumam executar compras de ações mais ilíquidas e de empresas menores em que o fundo já apresenta uma posição excessiva no último dia do trimestre, o que faz com que o preço dessas ações apresente um retorno anormal positivo nesse dia, melhorando, consequentemente, o desempenho do fundo naquele instante de tempo. Carhart et al. (2002) também encontram indícios de que alguns fundos mútuos manipulam o preço de ações em que já detêm posições. Essa prática de buscar inflacionar os preços de ativos que já estão com participação excessiva na carteira (overweight) é conhecida como portfolio pumping. ${ }^{3}$ Assim como encontrado em Carhart et al. (2002) e Gallagher et al. (2009) encontraram que os fundos australianos apresentam retornos diários no último dia do trimestre maiores do que os retornos nos índices de referência, indicando que esses fundos investem mais do que o investidor médio em ações que experimentam a inflação do dia de encerramento de trimestre.

Brown et al. (1996) analisam se os fundos que apresentam as piores performances no meio do ano, os "perdedores", alteram seu nível de risco de modo diferente do feito pelos fundos que no mesmo período estão apresentando desempenho superior, os fundos "vencedores". Os autores analisam os fundos mútuos de ações dos EUA classificados como "growth oriented" de 1976 a 1991. Mesmo na ausência de remuneração em função de desempenho relativo, como as taxas de performance, a competição na indústria de fundos mútuos pelos recursos dos investidores pode ser estímulo suficiente para os gestores alterarem o perfil de risco de suas carteiras com o objetivo de melhorar o desempenho. Para os autores, os gestores que se encontram nos extremos dos desempenhos têm incentivos para alterar a composição de suas carteiras com o objetivo de maximizar sua remuneração esperada, sendo que os "perdedores" aumentam seu nível de risco relativamente ao grupo dos potenciais "vencedores".

As evidências encontradas por Brown et al. (1996) foram de que os fundos classificados como "perdedores" no meio do ano aumentaram o risco de suas carteiras para o restante do ano quando comparados as fundos "vencedores", sendo que esse aumento de risco se torna mais pronunciado para os fundos mais novos. Além disso, a estratégia dos fundos "perdedores" aumentar o nível de risco depois do meio do ano para tentar recuperar o terreno perdido se intensificou nos últimos cinco anos da amostra. Para os autores, o crescimento da indústria de fundos mútuos no período final de sua amostra, aliado ao maior escrutínio por parte dos investidores com relação a desempenhos passados dos fundos podem ser os responsáveis por esse comportamento dos gestores de assumir posições de maior risco quando seu desempenho é relativamente inferior.

Huang et al. (2011) também analisam a performance de fundos mútuos dos EUA que apresentam mudanças em seus níveis de risco ao longo do tempo. Eles comparam a volatilidade computada com base nas posições das carteiras divulgadas nos encerramentos dos trimestres com a volatilidade realizada do

\footnotetext{
${ }^{3}$ Essa prática difere do window dressing. Na prática de portfolio pumping, o objetivo é comprar ações que já fazem parte da carteira, especialmente aquelas em que a concentração é maior, de forma a tentar elevar artificialmente seus preços. O window dressing tem como objetivo livrarse das ações perdedoras e comprar as ações vencedoras, de maneira a apresentar uma carteira composta majoritariamente por ações vencedoras. Nesse caso, haveria pressão para que os preços das ações perdedoras caíssem, enquanto o preço das ações vencedoras ficaria pressionado para cima. No portfolio pumping busca-se criar apenas a pressão de preço para cima.
} 
retorno das cotas dos fundos mútuos. A primeira representa a volatilidade do fundo caso o gestor mantivesse a posição registrada no encerramento do trimestre, a última é a volatilidade efetivamente percebida pelos investidores do fundo. As evidências encontradas são de que a volatilidade da carteira do encerramento de trimestre é diferente da volatilidade realizada do fundo, indicando que os gestores alteram o nível de risco a que os fundos são submetidos nos encerramentos de trimestre.

A alteração do patamar de risco assumido por um fundo pode ser um indicativo de problemas de agência, como já havia sido apontado por Grinblatt \& Titman (1989). Por um lado, o risco de um fundo pode ser alterado em função de negociações deletérias (ill-motivated) do fundo feitas com o intuito de aumentar a remuneração do gestor. Por outro lado, os gestores podem ser motivados a alterar o perfil do risco a que as carteiras estão expostas para se aproveitarem da relação convexa entre performance e fluxo de recursos, isto é, enquanto os fundos que apresentam desempenho superior recebem maiores aportes de capital, aqueles que registram desempenho inferior sofrem reduções nos recursos geridos em menor proporção do que os ingressos de capital nos fundos de melhor desempenho. Essa relação convexa pode criar incentivos para o gestor aumentar o nível de risco da carteira com vistas a obter um desempenho superior.

Os resultados encontrados por Huang et al. (2011) indicam que os fundos alteram significativamente o nível de risco ao longo do tempo, sendo que os fundos que mais alteram seus patamares de risco acabam apresentando desempenho inferior aos que mantêm uma estabilidade no nível de risco. Desse modo, os investidores se encontram em melhor situação quando deixam seus recursos em fundos que mantêm o nível de risco estável. De acordo com os autores, as mudanças nos níveis de risco dos fundos são provavelmente indicativos dos problemas de agência na gestão profissional de recursos, seja para o gestor explorar a convexidade da relação entre desempenho e fluxos de capitais, seja para ele obter uma maior compensação.

Assim como encontrado em Brown et al. (1996) e Huang et al. (2011), Warner \& Wu (2011) encontram indícios de problemas de agência na gestão profissional de carteiras, em que os gestores buscam se aproveitar da assimetria entre o desempenho e o fluxo de recursos geridos, aumentando sua remuneração quando o desempenho apresentado é positivo, mas não sofrendo um corte em sua remuneração para um desempenho fraco. Uma possível maneira de reduzir esse problema seria por meio da manutenção de uma maior proporção de conselheiros independentes, pois Warner \& Wu (2011) encontram que um maior grau de independência do conselho do fundo mútuo está associado com menores incidências de aumentos na remuneração dos gestores e a maiores ocorrências de reduções nos contratos de remuneração dos gestores.

Gallagher et al. (2009) também estudam se mudanças na metodologia do preço de fechamento na Australia Securities Exchange (ASX) alteraram o comportamento dos gestores dos fundos institucionais na Austrália. No caso australiano, para a formação do preço de fechamento foi adotado um modelo de leilão discreto em fevereiro de 1997, sob o argumento de possíveis manipulações dos preços de fechamento para influenciar os preços de contratos futuros. Após novas alegações de manipulações de preços, a metodologia da cotação de fechamento na ASX foi novamente alterada em 2001. Os leilões de fechamento foram desenhados de forma a propiciar uma maior liquidez no fechamento e também como forma de reduzir a oportunidade dos gestores 
inflacionarem temporariamente os preços. Segundo os autores, com a introdução dos leilões a possibilidade de manipular os preços de fechamento caiu, uma vez que a volatilidade dos preços no fechamento foi reduzida. Segundo eles, apesar de ter sido reduzida, a probabilidade de inflacionar temporariamente os preços não foi totalmente eliminada.

Com base no levantamento de informações sobre processos judiciais envolvendo manipulação de preços de ações nos mercados dos EUA e do Canadá, Comerton-Forde \& Putnins (2011) realizam estimativas por meio da metodologia de diferenças-em-diferenças (DID - differences-in-differences). Os autores analisam variáveis construídas com base nos momentos finais do pregão, como, por exemplo, retorno na última meia hora de negociação, para analisar a possibilidade de ocorrência de manipulação dos preços. Na estimativa DID, os autores buscam ver se a variável de interesse para a ação suspeita de manipulação antes e depois da possível manipulação difere do comportamento das outras ações do mercado antes e depois dessa manipulação. Com base nos casos de manipulação estudados, os autores concluem que, apesar da manipulação durar um curto intervalo de tempo, os preços podem acabar ficando muito distantes de seus valores ideais em função da manipulação, o que pode ter efeitos deletérios no mercado, como uma redução de liquidez.

\section{Amostra}

A amostra da pesquisa é constituída pelos fundos de investimento em ações (FIAs) desde o início do ano de 2004 a fevereiro de 2012. As informações dos fundos foram fornecidos pela base de dados Quantum Axis ${ }^{\circledR}$. O valor da cota (Net Asset Value - NAV) e o patrimônio líquido dos fundos têm periodicidade diária.

As taxas de administração e performance, bem como o tipo de clientela a que os fundos são destinados, também são compiladas pelo banco de dados da Quantum Axis ${ }^{\circledR}$. Neste trabalho, um fundo é classificado entre fundo que cobra taxa de performance (Perf) ou não $(A d m)$, e pelo tipo de investidor a que é destinado (Geral ou Qualif) com base nos valores vigentes no momento da coleta dos dados, fevereiro de 2012, como se essas características do fundo fossem mantidas constantes para todo o período da amostra.

Os fundos sob análise são os classificados pela Quantum ${ }^{\circledR}$ como "Ações Ativo". Essa classificação elimina os fundos setoriais, os de private equity, os fundos de índice e os ETFs (Exchange Traded Funds). Ao fim do período amostral, 902 fundos faziam parte dessa classificação. Dos 902 fundos, 369 (41\% do total) são destinados ao público geral e 533 (59\% do total) são voltados a investidores qualificados. Tanto nos fundos limitados aos investidores qualificados quanto nos fundos destinados ao público geral, aqueles em que há cobrança de taxa de performance são minoria em número e em montante de recursos sob gestão.

Uma ressalva a ser feita com relação aos dados analisados nesta pesquisa é que as informações dos fundos descontinuados não são mantidas na base de dados. A Comissão de Valores Mobiliários também descarta o acesso em sua página da internet aos dados referentes aos fundos descontinuados. Dessa forma, os fundos que foram analisados são aqueles que estão em funcionamento no momento da coleta dos dados. Com isso, os resultados apresentados podem ser influenciados pelo viés de sobrevivência. 
Consideramos o período selecionado para a pesquisa como representativo para a análise da atuação dos gestores. Em períodos anteriores ao escolhido os fundos existiam em menor quantidade e administravam um patrimônio pequeno. No período em questão a indústria dos FIAs experimentou um significativo crescimento, sendo que uma regulação mais abrangente foi formalizada em agosto de 2004 com a vigência da Instrução CVM no 409.

A Tabela 1 apresenta o número de FIAs e o valor dos ativos sob gestão (Assets Under Management - AUM). A indústria de fundos mútuos apresentou forte crescimento ao longo do período amostral. Entre os fundos em funcionamento no momento da coleta das informações, a quantidade de fundos e o AUM cresceram no período por um fator próximo a 7 . Os fundos destinados ao público geral que não cobram taxa de performance (AdmGeral) administram a maior parcela dos recursos do público geral, que também pode investir em fundos em que existe a cobrança da taxa de performance (PerfGeral). Os fundos voltados aos investidores qualificados que não cobram taxa de performance (AdmQualif) foram os que apresentaram o maior crescimento tanto do montante de recursos de gestão (um fator de aproximadamente 8,5 ) quanto do número de fundos (um fator de aproximadamente 15,4). Os fundos voltados aos investidores qualificados em que existe a cobrança de taxa de performance (PerfQualif) cresceram por um fator de 5,25 nos recursos geridos e de quase 14 no número de fundos.

Também cabe mencionar o maior crescimento no número de fundos que cobram taxa de performance para ambas as clientelas em comparação aos FIAs em que ela não é cobrada, usualmente sendo cobrada apenas a taxa de administração. Os fundos que cobram taxa de performance cresceram em número por um fator de 8,7 , enquanto os fundos que não cobram a taxa de performance apresentaram crescimento no número de fundos por um fator de cerca de 6,6. Sob a ótica do AUM, contudo, o fator de crescimento dos fundos que não cobram taxa de performance foi de cerca de 7,4, enquanto os fundos que cobram taxa de performance apresentaram crescimento do AUM por um fator de 5. Com isso, os indícios apontam para uma disseminação dos contratos que bonificam os gestores que obtêm performance positiva, ainda que o montante de recursos tenha crescido mais nos fundos que não cobram taxa de performance.

Tabela 1: Número de FIAs e total de ativos sob gestão em $\mathrm{R} \$$ bilhões

\begin{tabular}{rrrrrrrrrrr}
\hline & \multicolumn{2}{c}{ AdmGeral } & \multicolumn{2}{c}{ AdmQualif } & \multicolumn{2}{c}{ PerfGeral } & \multicolumn{2}{c}{ PerfQualif } & \multicolumn{2}{c}{ Todos } \\
\cline { 2 - 11 } & Qtde & AUM & Qtde & AUM & Qtde & AUM & Qtde & AUM & Qtde & AUM \\
\hline 2004 & 65 & 3,6 & 22 & 5,9 & 24 & 0,8 & 14 & 2,1 & 125 & 12,4 \\
2005 & 72 & 4,1 & 32 & 8,6 & 27 & 0,9 & 22 & 2,1 & 153 & 15,7 \\
2006 & 78 & 6,6 & 53 & 13,2 & 34 & 1,5 & 33 & 2,7 & 198 & 24,0 \\
2007 & 97 & 15,0 & 105 & 25,4 & 49 & 4,0 & 52 & 5,0 & 303 & 49,4 \\
2008 & 127 & 8,3 & 163 & 21,9 & 74 & 1,6 & 90 & 3,8 & 454 & 35,6 \\
2009 & 144 & 16,3 & 220 & 33,1 & 88 & 3,4 & 114 & 7,6 & 566 & 60,5 \\
2010 & 192 & 18,8 & 285 & 48,5 & 107 & 3,9 & 163 & 10,3 & 747 & 81,4 \\
2011 & 232 & 19,8 & 339 & 49,8 & 137 & 3,7 & 194 & 10,8 & 902 & 84,1 \\
\hline
\end{tabular}




\subsection{Dados de fundos descontinuados}

A Quantum ${ }^{\circledR}$ gentilmente disponibilizou alguns dados sobre FIAs que estiveram em funcionamento durante o período amostral, mas que no momento da coleta dos dados já tinham sido descontinuados, de forma que não estavam presentes na base de dados que foi utilizada na pesquisa.

Os dados dos fundos descontinuados não apresentam periodicidade diária, de modo que não foi possível analisar o comportamento dos retornos anormais nos encerramentos e inícios de período para esses fundos. Além disso, também não foi possível obter informações sobre os contratos de remuneração e a clientela a que esses fundos são destinados.

A Tabela 2 apresenta o número de fundos e o AUM dos fundos que estão presentes na base de dados, como já apresentado na Tabela 1, bem como as informações dos FIAs que existiam durante o período amostral mas que haviam sido descontinuados no momento da coleta dos dados.

Tabela 2: FIAs descontinuados

\begin{tabular}{ccccccccr}
\hline & \multicolumn{2}{c}{ Todos (I) } & \multicolumn{2}{c}{ Descontinuados (II) } & \multicolumn{2}{c}{ I + II } & \multicolumn{2}{c}{ II / (I + II) } \\
\cline { 2 - 8 } & Qtde & AUM & Qtde & AUM & Qtde & AUM & Qtde & AUM \\
\hline 2004 & 125 & 12,4 & 95 & 3,2 & 220 & 15,6 & $43 \%$ & $21 \%$ \\
2005 & 153 & 15,7 & 87 & 3,2 & 240 & 18,8 & $36 \%$ & $17 \%$ \\
2006 & 198 & 24,0 & 104 & 5,5 & 302 & 29,5 & $34 \%$ & $19 \%$ \\
2007 & 303 & 49,4 & 146 & 7,3 & 449 & 56,7 & $33 \%$ & $13 \%$ \\
2008 & 454 & 35,6 & 139 & 3,5 & 593 & 39,1 & $23 \%$ & $9 \%$ \\
2009 & 566 & 60,5 & 101 & 3,0 & 667 & 63,4 & $15 \%$ & $5 \%$ \\
2010 & 747 & 81,4 & 91 & 2,9 & 838 & 84,3 & $11 \%$ & $3 \%$ \\
2011 & 902 & 84,1 & 21 & 0,5 & 923 & 84,7 & $2 \%$ & $1 \%$ \\
\hline
\end{tabular}

Nota: Ativos sob gestão (AUM) em R $\$$ bilhões.

Ao final do ano de 2004, os fundos descontinuados representavam $43 \%$ dos fundos em quantidade, mas apenas $21 \%$ dos ativos sob gestão pelos fundos de investimento em ações. Essas proporções diminuem ao longo do tempo, chegando a $2 \%$ do número total de fundos e $1 \%$ dos recursos sob gestão ao final de 2011.

Ainda que se considerem os fundos que não estavam presentes na amostra, o crescimento por que passou a indústria dos fundos de investimento em ações foi expressivo no período. O número de fundos existentes passou a ser 4,2 vezes maior, enquanto os recursos geridos cresceram por um fator de 5,4.

\section{Metodologia e resultados}

Para analisar se os FIAs apresentam um comportamento anormal nos encerramentos do período, será considerado como retorno anormal de um fundo o excesso de retorno do fundo em relação ao principal índice de referência do mercado acionário brasileiro, o índice Ibovespa, divulgado pela BM\&FBovespa. ${ }^{4}$

Em linha com o feito por Carhart et al. (2002), construímos carteiras hipotéticas dos FIAs para analisarmos a presença ou não de retornos anormais

\footnotetext{
${ }^{4}$ Alternativamente, foi utilizado o IBrX como índice de referência. Os resultados não alteram as conclusões.
} 
nos encerramentos de período e a reversão desse retorno no dia seguinte ao encerramento. No entanto, em vez de criar carteiras de fundos com base nos "estilos" dos fundos, serão construídas carteiras com base na presença ou não da taxa de performance, na limitação a investidores qualificados ou se o fundo é aberto ao público geral.

As carteiras dos FIAs foram construídas de duas maneiras: (1) atribuindo peso igual para cada um dos fundos existentes (EW - equally weighted), ou (2) ponderando pelo valor do patrimônio líquido (PL) de cada fundo (VW value weighted). ${ }^{5}$ As carteiras foram construídas levando em conta todos os fundos presentes na amostra $(\mathrm{All})$, apenas os fundos que já existiam desde o início da amostra (old) ou então os fundos que possuíam PL superior a R $\$ 1$ milhão (size). Ao considerar apenas os fundos com PL superior a R\$ 1 milhão, um fundo é desconsiderado da amostra apenas nos períodos em que a condição de tamanho não é satisfeita. Não são consideradas as médias de patrimônio mensal ou anual, por exemplo, para determinar se o fundo será ou não descartado. Apenas é levado em conta o patrimônio líquido divulgado no dia como critério de inclusão.

As carteiras construídas apenas com fundos em que não havia cobrança da taxa de performance e incluindo tanto os fundos voltados ao público geral quanto os fundos destinados a investidores qualificados foram chamadas de " $A d m$ ". De forma análoga, as carteiras de fundos em que a cobrança da taxa de performance estava presente, independente da clientela a que se destinam os fundos, foram denominadas "Perf". Para as carteiras construídas com os fundos destinados apenas ao público geral, ocorrendo ou não a cobrança da taxa de performance, foi dado o nome de "Geral". As carteiras de fundos dedicados apenas a investidores qualificados, estando presente ou não a taxa de performance, foram denominadas "Qualif".

$\mathrm{Na}$ Tabela 3, são apresentados os fatores de retorno pelos quais os valores das carteiras dos índices de referência evoluíram desde o início de 2004 até 13/fev/2012. No Painel A, são apresentados os valores para os principais índices de referência do mercado acionário brasileiro, o Índice Ibovespa (Ibov) e o IBrX, bem como os resultados das carteiras construídas levando em conta todos os FIAs da amostra, pelas ponderações EW e VW. No Painel B, os resultados são apresentados para as carteiras construídas utilizando a mesma ponderação para todos os fundos, EW, enquanto no Painel C o patrimônio líquido dos fundos é usado como critério de ponderação, VW. Na parte de baixo dos dois últimos painéis, são apresentados os resultados considerando todos os fundos da amostra e fazendo a distinção entre a presença ou não da taxa de performance bem como o tipo de clientela a que os fundos se destinam.

Ao comparar as carteiras formadas com todos os fundos, seja pelo critério EW, seja pelo VW, os resultados apontam que os fundos apresentam ao longo do período da análise retornos superiores aos registrados pelos dois índices de referência, o Ibovespa e o IBrX, conforme mostrado no Painel A da Tabela 3. Esse resultado diverge dos indícios encontrados na literatura que apontam que os fundos costumam apresentar retornos líquidos menores do que os índices de referência. Uma vez que a base de dados utilizada só considera os fundos que estavam em funcionamento no momento da coleta, o resultado

\footnotetext{
${ }^{5}$ Também foram desconsiderados os cinco primeiros dias úteis de existência dos fundos, para aqueles que se iniciaram durante o período da amostra. Essa eliminação tem por objetivo eliminar os valores retornos distorcidos por conta do descasamento entre os ativos do fundo e o valor a ser convertido em patrimônio líquido do fundo
} 
Tabela 3: Fator de retorno das carteiras dos FIAs

\begin{tabular}{|c|c|c|c|c|}
\hline \multicolumn{5}{|c|}{ Painel A - Benchmark vs. Todos } \\
\hline & Ibov & $\mathrm{IBrX}$ & All EW & All VW \\
\hline All & 2,94 & 3,61 & 3,89 & 4,63 \\
\hline Old & & & 3,18 & 4,82 \\
\hline Size & & & 3,88 & 4,58 \\
\hline \multicolumn{5}{|c|}{ Painel B - EW } \\
\hline & Adm & Perf & Geral & Qualif \\
\hline All & 3,87 & 3,92 & 3,44 & 4,41 \\
\hline Old & 3,07 & 3,45 & 2,96 & 3,88 \\
\hline \multirow[t]{4}{*}{ Size } & 3,86 & 3,90 & 3,43 & 4,38 \\
\hline & & Adm & Perf & \\
\hline & Geral & 3,32 & 3,69 & \\
\hline & Qualif & 4,62 & 4,03 & \\
\hline \multicolumn{5}{|c|}{ Painel C - VW } \\
\hline & Adm & Perf & Geral & Qualif \\
\hline All & 4,89 & 3,70 & 3,38 & 5,55 \\
\hline Old & 5,11 & 3,76 & 3,26 & 5,91 \\
\hline \multirow[t]{4}{*}{ Size } & 4,83 & 3,66 & 3,28 & 5,52 \\
\hline & & Adm & Perf & \\
\hline & Geral & 3,47 & 3,04 & \\
\hline & Qualif & 5,99 & 4,14 & \\
\hline
\end{tabular}

encontrado indica que pode haver um problema de viés de sobrevivência. Entretanto, quando se consideram apenas os fundos desde o começo da amostra (old), pela ponderação EW, o retorno da carteira fica entre os dois principais benchmarks.

Ainda no Painel A da Tabela 3, tem-se que os índices VW apresentaram maiores valores do que os $\mathrm{EW}$, indicando que os fundos maiores tiveram desempenho superior aos fundos pequenos. Esses resultados são indícios de que: (1) os ganhos de escala podem ser relevantes, (2) fundos maiores são administrados por gestores mais capacitados, (3) fundos que são capazes de gerar maiores retornos atraem novos fluxos de capital, e/ou (4) os investidores preferem ou têm acesso mais fácil a fundos maiores, talvez distribuídos pela rede de varejo dos bancos.

Comparando os resultados para as carteiras dos fundos que cobram a taxa de performance (Perf) ou não $(A d m)$ apresentados nos Painéis B e C da Tabela 3 , os fundos em que a taxa de performance é cobrada acabam tendo desempenho inferior quando considerada a ponderação pelo patrimônio dos fundos. $\mathrm{Na}$ ponderação EW, os fundos que cobram a taxa de performance acabam tendo uma performance superior aos que não a cobram. 
Quando as carteiras são criadas levando em consideração se ele é destinado ao público geral ou limitado a investidores qualificados, os resultados apontam, para qualquer critério, que o retorno dos fundos limitados a investidores qualificados é muito superior aos obtidos nos fundos abertos ao público geral. Esse resultado pode ser um indício de que (1) o investidor qualificado tem uma capacidade de monitorar o comportamento do gestor superior em relação ao público geral, reduzindo o problema de agência presente na gestão profissional de recursos, e/ou (2) a possibilidade de atuar sob regras menos rígidas para os fundos restritos aos investidores qualificados permite ao gestor empregar estratégias mais sofisticadas, ou assumir maiores riscos, para essa clientela do que para o público geral, o que no período da amostra significou um retorno maior.

Para os fundos destinados a investidores qualificados, o desempenho das carteiras de fundos em que não há cobrança da taxa de performance é muito superior ao daqueles que cobram esse encargo, o que pode ser indício de quanto a taxa de performance onera o investidor e/ou de um possível problema de agência. Cabe destacar que o resultado obtido pelas carteiras dos fundos voltados a investidores qualificados, por qualquer ponderação e pela incidência ou não da taxa de performance, foram superiores aos desempenhos registrados pelos índices de referência.

Na primeira subseção, todo o período amostral, do início de 2004 a fevereiro de 2012, é analisado. A segunda subseção faz a distinção entre o período em que a marcação a mercado dos fundos era feita por meio do preço médio e o período em que ela era feita pelo preço de fechamento, a partir de maio de 2008.

\subsection{Todo o período amostral}

\section{Carteiras dos FIAs}

Para calcular a anormalidade dos retornos das carteiras dos FIAs nos encerramentos dos períodos, foi adotado um método semelhante ao de Carhart et al. (2002). O retorno anormal diário é definido como o excesso de retorno da carteira em relação ao índice Ibovespa. O retorno anormal diário é a variável dependente dos diferentes modelos. As variáveis explicativas são uma constante e as variáveis de encerramento e de início de período são construídas do seguinte modo:

- S1END (S1BEG) assume o valor 1 no último (primeiro) dia de negociação na BM\&FBovespa do $1^{\circ}$ semestre. Caso contrário, zero.

- S2END (S2BEG) assume o valor 1 no último (primeiro) dia de negociação na BM\&FBovespa do $2^{\circ}$ semestre. Caso contrário, zero.

- SEND (SBEG) assume o valor 1 no último (primeiro) dia de negociação na BM\&FBovespa do $1^{\circ}$ ou $2^{\circ}$ semestre. Caso contrário, zero.

- MEND (MBEG) assume o valor 1 no último (primeiro) dia de negociação na BM\&FBovespa dos meses que não sejam os de encerramento (início) do semestre. Caso contrário, zero.

- END (BEG) assume o valor 1 no último (primeiro) dia de negociação do mês, independente de ser encerramento (início) do semestre. Caso contrário, zero. 
Na Tabela 4, são apresentados os resultados para os retornos anormais em relação ao índice Ibovespa quando todos os fundos da amostra são considerados para a construção das carteiras de fundos. No Painel A, as carteiras dos fundos são construídas com a ponderação igual para os fundos, enquanto no Painel B os pesos atribuídos aos fundos são construídos como a proporção entre seu patrimônio em relação ao patrimônio total dos fundos da mesma classificação. Os valores dos coeficientes representam porcentuais, de forma que o valor do coeficiente para a variável $E N D$ no modelo que leva em conta todos os fundos $(A l l)$ com a ponderação EW (Painel A) de 0,09 significa 0,09\%, ou 9 pontos base. O valor apresentado abaixo dos coeficientes representa a estatística $t$, já utilizando os desvios-padrão robustos de White, sendo que os valores maiores do que 2 em termos absolutos estão em negrito. $\mathrm{O}$ primeiro modelo busca verificar se os finais (inícios) do primeiro e do segundo semestre, bem como os finais (inícios) de mês, apresentam retornos anormais - Equação 2. O segundo modelo considera apenas as datas de encerramento e início dos semestres, sem fazer distinção entre os semestres - Equação 3. O terceiro modelo faz a distinção entre o primeiro e o segundo semestre, bem como dos meses que não coincidem com as datas do início e encerramento do semestre - Equação $4 .^{6}$

$$
\begin{gathered}
z_{i, t}=\beta_{i, 0}+\beta_{i, 1} E N D_{t}+\beta_{i, 2} B E G_{t}+\varepsilon_{1 i, t} \\
z_{i, t}=\beta_{i, 0}+\beta_{i, 1} S E N D_{t}+\beta_{i, 2} S B E G_{t}+\varepsilon_{2 i, t} \\
z_{i, t}=\beta_{i, 0}+\beta_{i, 1} S 1 E N D_{t}+\beta_{i, 2} S 2 E N D_{t}+\beta_{i, 3} S 1 B E G_{t}+ \\
\beta_{i, 4} S 2 B E G_{t}+\beta_{i, 5} M E N D_{t}+\beta_{i, 6} E N D_{t}+\varepsilon_{3 i, t}
\end{gathered}
$$

Caso os gestores dos FIAs atuem de modo a tentar inflacionar os valores das cotas nos encerramentos de período, os sinais dos coeficientes das variáveis de encerramento de período deveriam ser positivos. Além disso, se o gestor reverte a operação feita para inflacionar o valor da cota do fundo no dia seguinte, os sinais dos coeficientes das variáveis de início de período devem ser negativos.

Os resultados da Tabela 4 indicam que a anormalidade dos retornos nos encerramentos de período é estatisticamente diferente de zero com maior frequência nos modelos que adotam a ponderação igual para todos os fundos do que naqueles em que o patrimônio é levado em conta. Esses resultados são um primeiro indício de que os retornos anormais nos finais de período podem ocorrer com maior frequência nos fundos de menor tamanho, uma vez que a ocorrência de retornos anormais diminui quando o tamanho do fundo se torna critério de ponderação.

Considerando as carteiras formadas com todos os fundos da amostra (All), ou as carteiras formadas com os fundos em que não há cobrança da taxa de performance $(A d m)$, ainda sem fazer distinção entre as clientelas, os modelos apresentam os coeficientes com os sinais esperados em todos os casos, exceto

\footnotetext{
${ }^{6}$ Além desses modelos, foram construídos modelos que faziam a distinção entre o primeiro e o segundo semestre, mas não consideravam as variáveis de mês e também um modelo que emprega uma variável para os semestres, sem fazer distinção entre o primeiro ou o segundo, e outra para os meses. Esses modelos não foram apresentados na Tabela 4 para manter a parcimônia.
} 


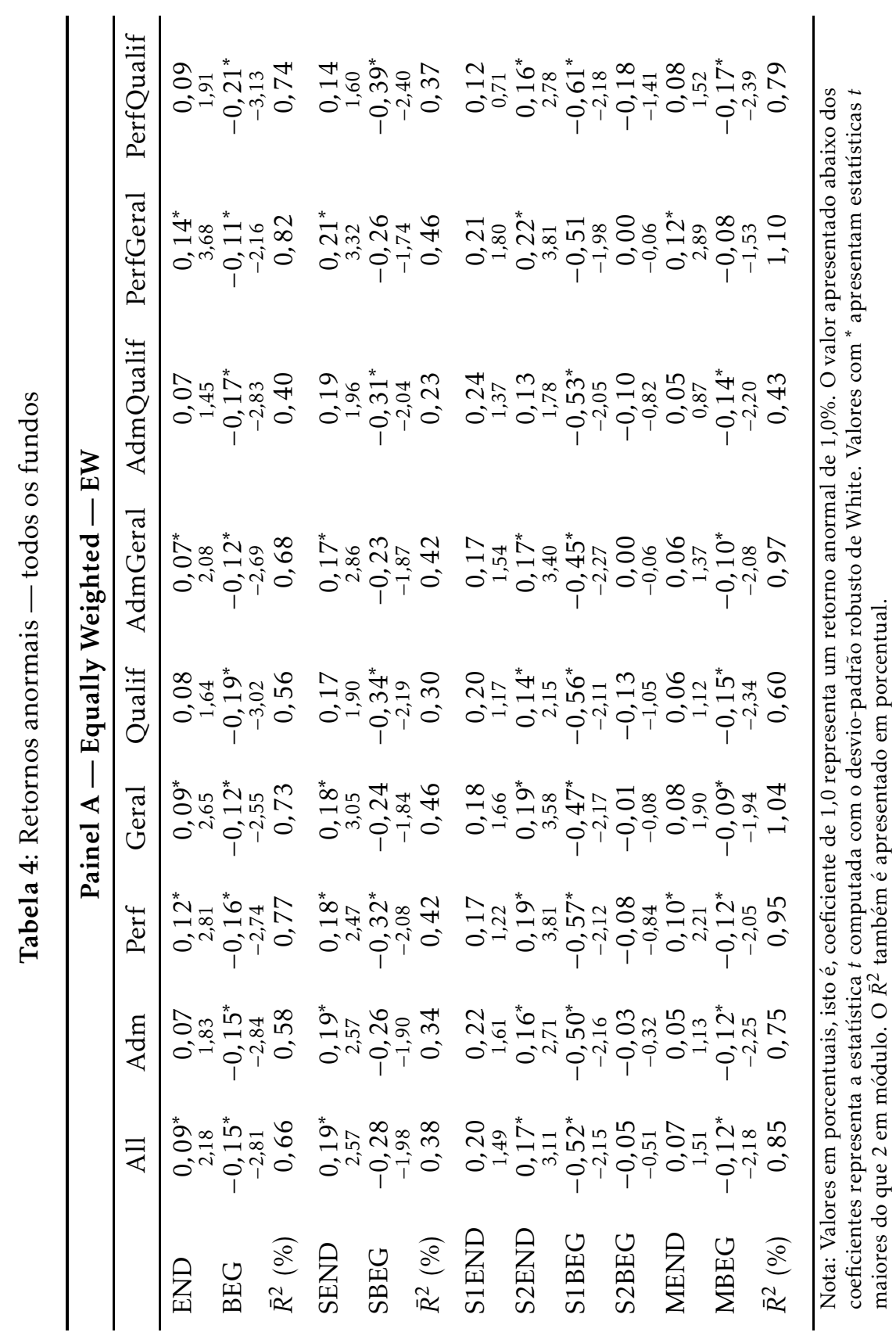




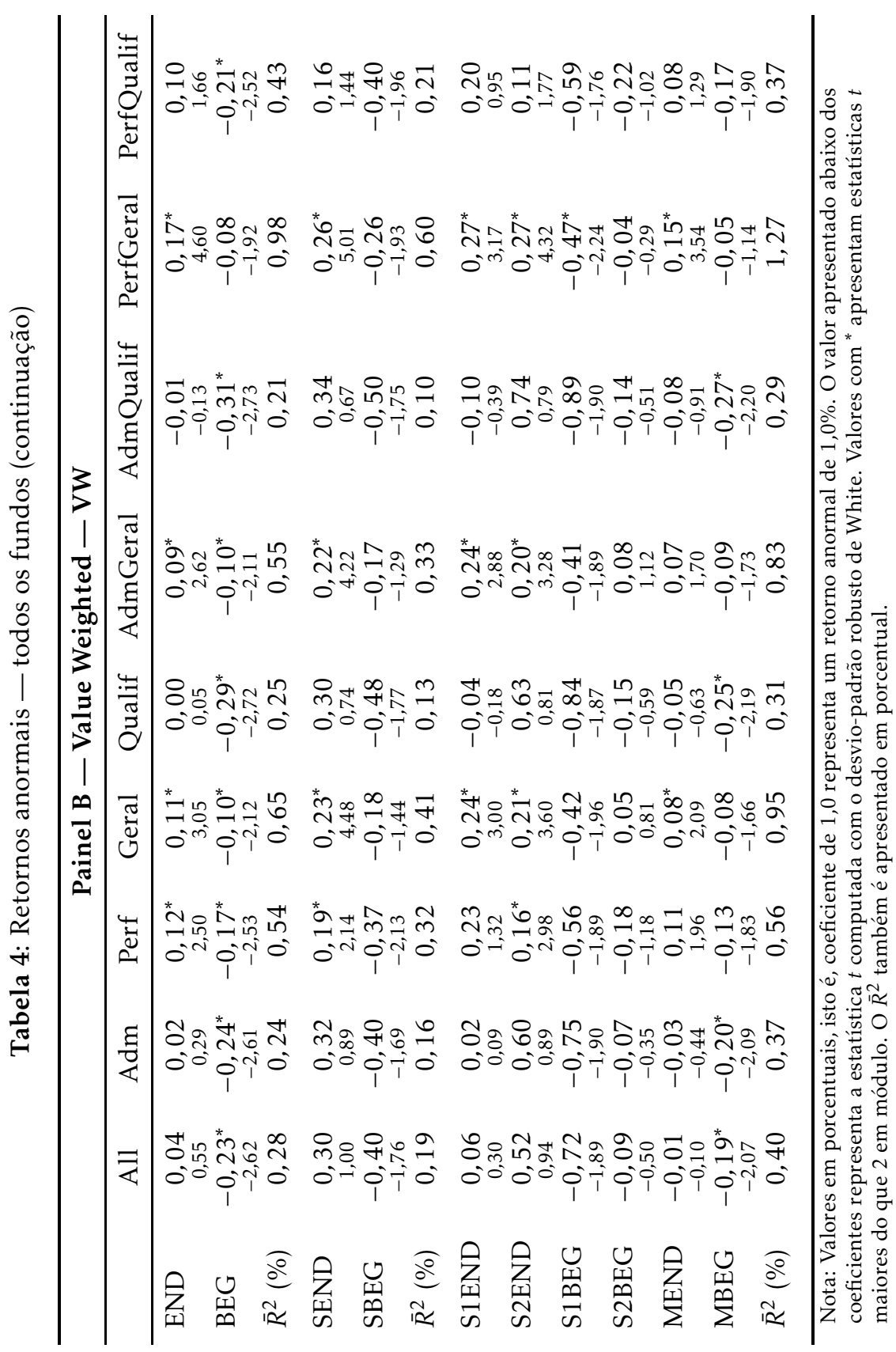


para o modelo da Equação 4, no caso da variável de encerramento do mês (MEND) para o modelo VW, cujo sinal esperado era positivo, mas o coeficiente estimado é pontualmente negativo, ainda que não seja estatisticamente significante. Na maioria dos casos, o valor absoluto do coeficiente estimado para a variável de início de período é maior do que a de encerramento do período, indicando que a estratégia de tentar inflacionar o valor da cota pode prejudicar o investidor.

Os resultados para as carteiras dos fundos em que ocorre a cobrança da taxa de performance (Perf) mostram indícios de que os gestores atuam de modo a tentar inflacionar o valor das cotas nos encerramentos de período. Nos modelos em que se consideram a ponderação VW, os coeficientes dos retornos anormais são estatisticamente significantes com maior frequência do que os casos das carteiras contruídas com todos os fundos $(A l l)$ ou nas carteiras em que não há cobrança da taxa de performance $(A d m)$.

Os modelos para as carteiras construídas apenas com fundos voltados ao público geral (Geral) apresentam uma maior ocorrência de retornos anormais estatisticamente significantes do que os modelos calculados para fundos destinados a investidores qualificados (Qualif) independente do critério de ponderação adotado. Esse resultado é um indício de que os investidores qualificados podem sofrer menos com problemas de agência do que o público geral.

Novas evidências de que os fundos voltados ao público geral são mais suscetíveis a problemas de agência por parte de seus gestores podem ser encontradas quando comparamos os resultados encontrados tanto para os fundos que não cobram taxa de performance destinados ao público geral (AdmGeral) frente aos voltados a investidores qualificados (AdmQualif) quanto para os fundos que cobram taxa de performance destinados ao público geral (PerfGeral) frente aos voltados a investidores qualificados (PerfQualif). A ocorrência de retornos anormais estatisticamente significantes é maior no caso dos modelos computados para fundos voltados ao público geral em ambas as comparações e adotando a ponderação EW ou VW.

As carteiras dos fundos que cobram taxa de performance voltados ao público geral (PerfGeral) também apresenta indícios de que os gestores tentam obter maiores remunerações ao produzirem maiores retornos anormais nos encerramentos de período, do que o encontrado nas carteiras de fundos sem a cobrança da taxa de performance voltados à mesma clientela (AdmGeral).

$\mathrm{Na}$ Tabela 5, são apresentados os resultados dos modelos quando as carteiras dos FIAs são construídas levando em conta apenas os fundos que já existiam desde o começo da amostra. Os resultados encontrados são bastante semelhantes aos encontrados quando todos os fundos são utilizados para a construção das carteiras, de forma que os potenciais problemas de agência nos FIAs podem afetar tanto os fundos mais recentes quanto os que tenham um histórico mais longo. Alternativamente, pode-se argumentar que esse problema de agência está presente nos fundos que têm conseguido se manter em funcionamento.

Dessa forma, os resultados indicam que pode haver um problema de agência nos FIAs, e que ele não está restrito aos fundos mais recentes. Esse problema está mais evidente nos fundos destinados ao público geral, indício de que a maior capacidade de monitoramento dos gestores pelos investidores qualificados pode atuar como um freio aos desvios de conduta por parte dos gestores. Com isso, as regras mais frouxas para a cobrança da taxa de performance nos fundos limitados exclusivamente a investidores qualificados não 


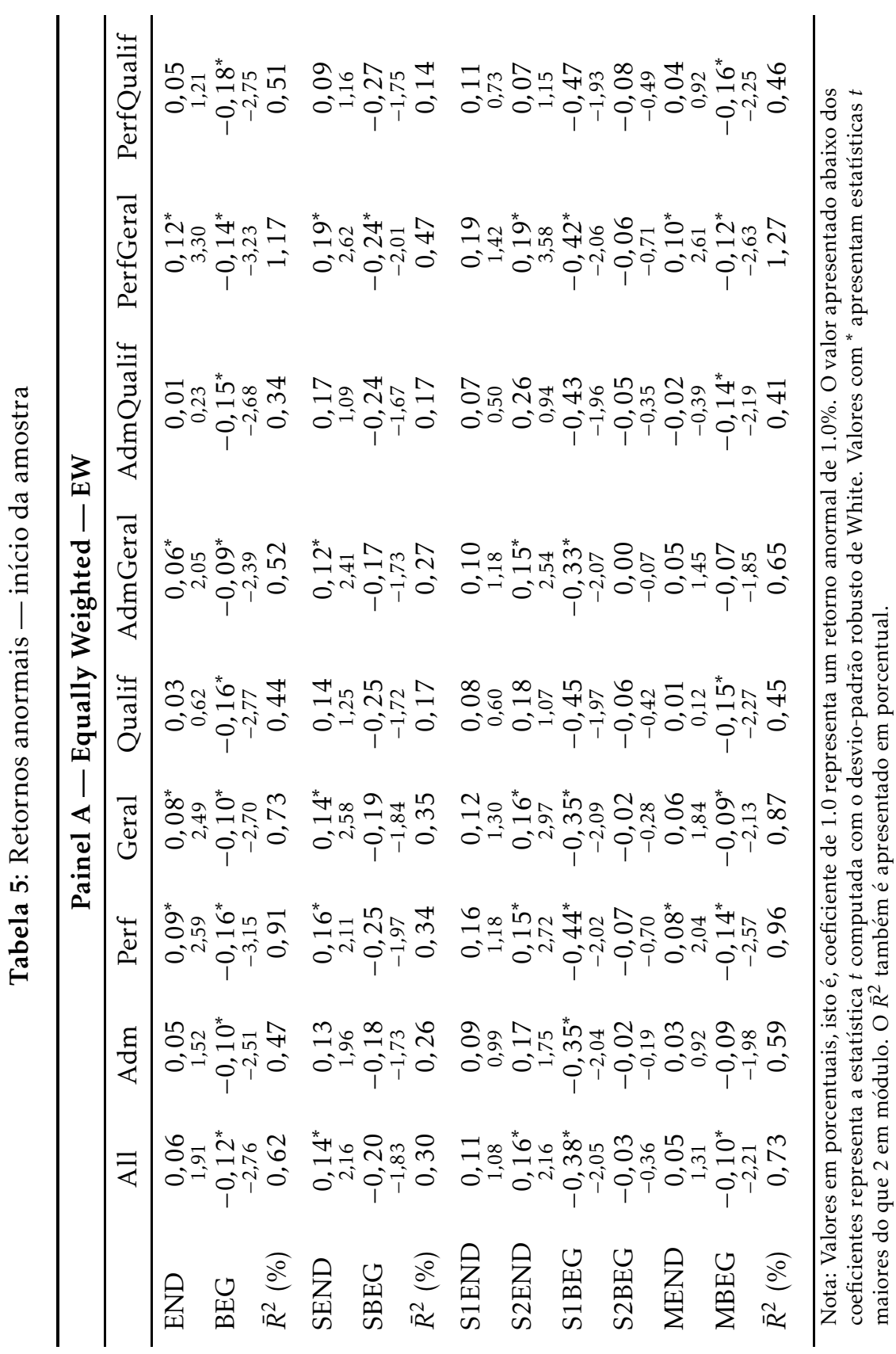




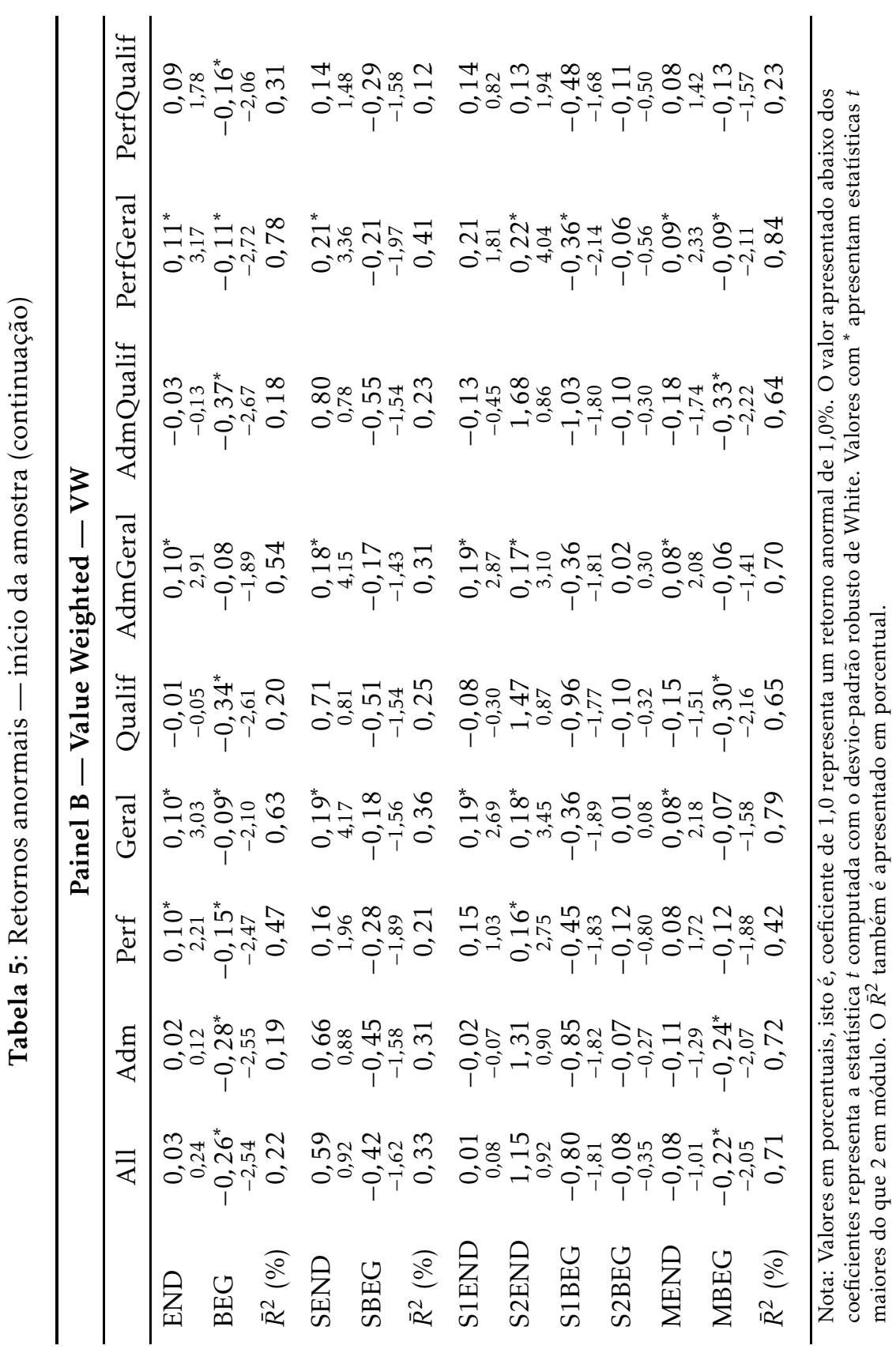


representam uma oportunidade para os gestores obterem desses investidores uma maior remuneração por meio da manipulação do valor da cota nos encerramentos de período. ${ }^{7}$

\section{Proporção de retornos anormais positivos}

Alternativamente à construção das carteiras dos FIAs, uma outra maneira adotada em Carhart et al. (2002) para testar a anormalidade dos retornos dos fundos mútuos de ações nos EUA foi substituir nas Equações 2 a 4 o retorno anormal das carteiras, $z_{i, t}$, pela proporção de fundos dentro da categoria considerada que apresentam retornos anormais positivos como variável dependente. Com essa alteração, o objetivo é verificar se a prática de tentar inflacionar o valor da cota nos encerramentos de período é uma prática disseminada entre os FIAs.

A Tabela 6 apresenta os resultados empregando a proporção de fundos que apresentam retornos anormais positivos como variável dependente. Os resultados indicam que uma maior proporção dos FIAs apresenta retornos anormais positivos nos encerramentos de períodos e uma menor proporção de FIAs apresenta retornos anormais positivos no dia seguinte ao encerramento dos períodos.

Assim como acontece para os modelos computados utilizando as carteiras dos FIAs, a proporção de retornos anormais positivos nos encerramentos de período para os fundos de investidores qualificados apresenta uma frequência menor de coeficientes estatisticamente significantes do que o caso dos fundos destinados ao público geral. Esses resultados representam novos indícios de que problemas de agência podem ser mais recorrentes em fundos destinados ao público geral.

\section{Análise individual dos FIAs}

Quando a análise foi feita com base na construção das carteiras dos FIAs ou com base na proporção de retornos anormais positivos, os períodos de encerramento considerados foram as datas de encerramento do calendário civil. Contudo, em alguns fundos, a taxa de performance é cobrada com base em

\footnotetext{
${ }^{7}$ Também foram feitos testes em que as variáveis do último e do primeiro dias foram substituídas. No lugar da variável do último dia foram utilizadas variáveis para um, dois ou três dias antes do encerramento do período. Analogamente, em vez da variável de início de período, foram usadas variáveis para um, dois ou três dias posteriores ao início do período. Os resultados não foram apresentados para manter a parcimônia.

Quando se utilizam a variável de um dia anterior ao encerramento do período e a variável do dia seguinte ao início do período, as evidências encontradas são de que não há retornos anormais nessas datas.

Adotando as variáveis de dois dias anteriores ao encerramento do período e dois dias depois do início do período, os resultados são de que os coeficientes para a variável de dois dias antes do encerramento do segundo semestre apresenta sinal negativo e estatisticamente significante. A variável do terceiro dia do segundo semestre apresentou coeficiente positivo e estatisticamente significante. Os sinais encontrados em ambos os casos foram contrários àqueles encontrados para o último e o primeiro dias dos períodos.

Empregando as variáveis de três dias anteriores ao encerramento do período e três dias após o início do período, os coeficientes que apresentam significância estatística são aqueles das variáveis para o quarto dia após o início do período, influenciado principalmente pela variável dos três dias após o início do primeiro semestre. Esses coeficientes apresentam valores positivos e estatisticamente significantes.
} 


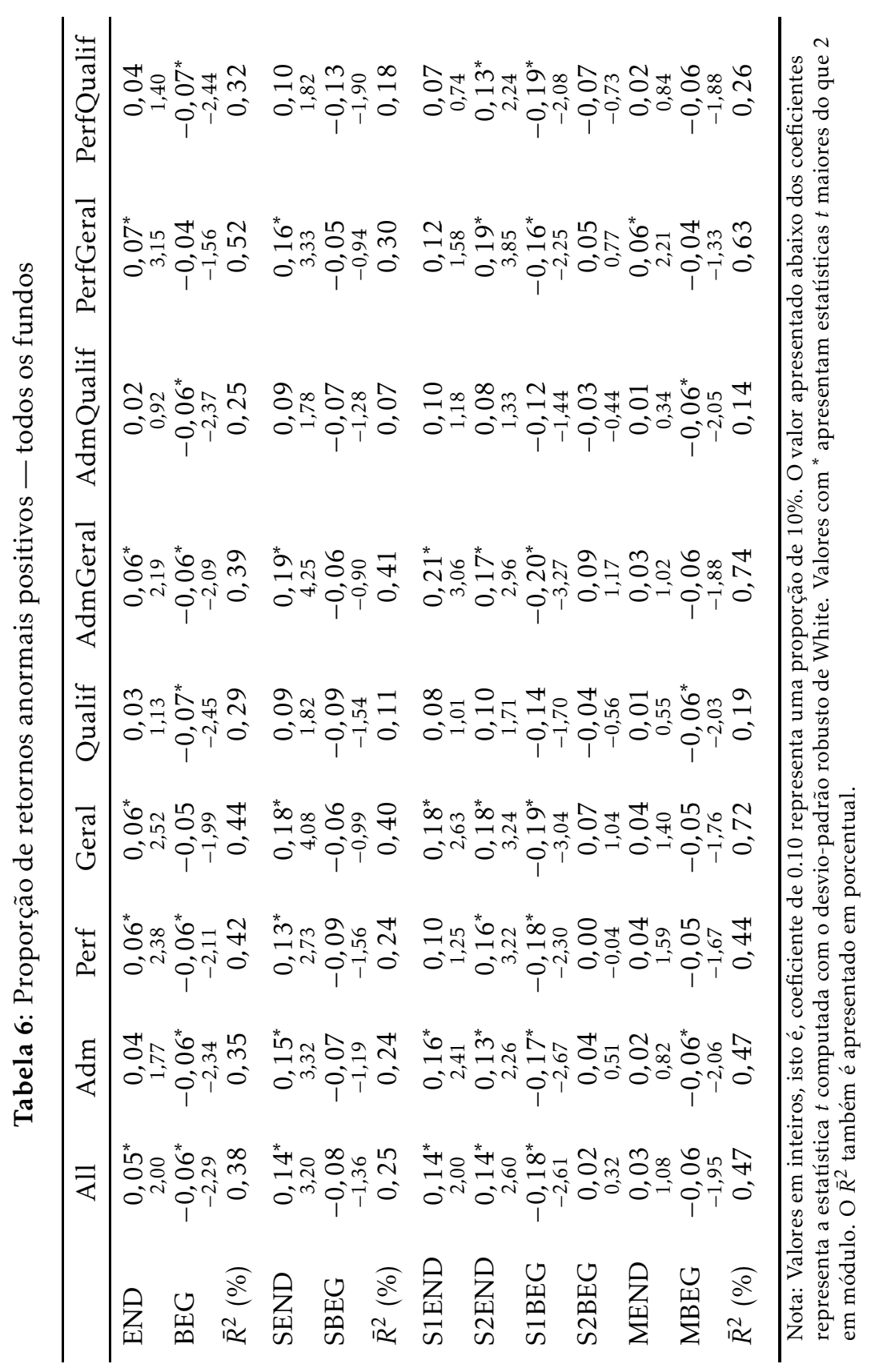


datas diferentes daquelas do calendário civil. ${ }^{8}$ Caso os gestores dos fundos estejam atuando de forma a tentar obter uma maior remuneração por meio da inflação no valor das cotas nas datas de encerramento de período que são relevantes para o fundo sob sua gestão, a estimação dos modelos anteriores pode não ter captado esse efeito.

A Tabela 7 apresenta as médias e medianas dos retornos anormais, novamente definidos como o excesso de retorno do fundo em relação ao índice Ibovespa, bem como a proporção de retornos anormais positivos e a quantidade de observações. Uma observação é composta por cada retorno anormal diário de cada fundo. Os valores das médias e medianas são apresentados em pontos-base, de forma que o valor de 25,8 representa um retorno anormal de 25,8 pontos bases, ou $0,258 \%$ diário. A coluna END representa os dados referentes ao último dia do período de apuração da taxa de performance, quando ela está presente nos fundos, ou então ao último dia do semestre civil, no caso dos fundos em que a taxa de performance não é cobrada. A coluna $B E G$ representa os dados referentes ao dia de negociação seguinte ao calculado na coluna $E N D$. Para os outros dias da amostra, cujos valores não foram reportados na tabela, a proporção de retornos anormais positivos fica em torno de $50 \%$ dos casos e a média e mediana ficam próximos a 1 ponto-base por dia. É provável que o viés de sobrevivência inerente à base de dados leve ao resultado de que os fundos obtêm um retorno médio diário superior ao obtido pelo índice de referência.

A proporção de retornos anormais em todos os casos é maior no dia do encerramento do período, passando de cerca de $50 \%$ para cerca de $67 \%$ quando considerados todos os fundos. Por outro lado, no dia seguinte ao encerramento, a proporção de retornos positivos cai para cerca de $36 \%$ das observações, considerando todos os fundos da amostra (All).

Os valores absolutos da média e mediana no dia de encerramento do período são menores do que os valores no dia seguinte, o que indica que a inflação do valor da cota no encerramento do período tem um custo elevado para o investidor, representado pelo retorno anormal negativo no dia seguinte ao encerramento do período.

Esses resultados estão em linha com os que haviam sido encontrados quando foram estimados os modelos que utilizavam o retorno anormal das carteiras hipotéticas dos FIAs ou pela proporção de retornos anormais positivos como variáveis dependentes.

\subsection{Alteração para o preço de fechamento}

Em maio de 2008, a marcação a mercado dos FIAs foi alterada. Pela nova regra, o valor dos ativos nas carteiras dos fundos deveria ser dado pelo preço de fechamento, não mais pelo preço médio ponderado pelo volume financeiro dos negócios. Essa mudança pode ter permitido aos gestores que ten-

\footnotetext{
${ }^{8}$ Dos 137 FIAs que no final de 2011 cobravam taxa de performance e eram voltados ao público geral, 18 fundos adotam um calendário para a cobrança da taxa de performance diferente do calendário civil, sendo que a periodicidade da cobrança da taxa de performance é semestral. Em 2 casos, a taxa de performance é cobrada com periodicidade anual. Dos 194 FIAs destinados a investidores qualificados que cobram taxa de performance, em 3 FIAs a periodicidade da cobrança é mensal (calendário civil), em 2 FIAs a cobrança é trimestral (calendário civil) e em 16 FIAs a cobrança é anual. Dos 173 fundos em que a cobrança ocorre com periodicidade semestral, em 21 deles a cobrança da taxa de performance ocorre em datas diferentes às do encerramento do calendário civil.
} 


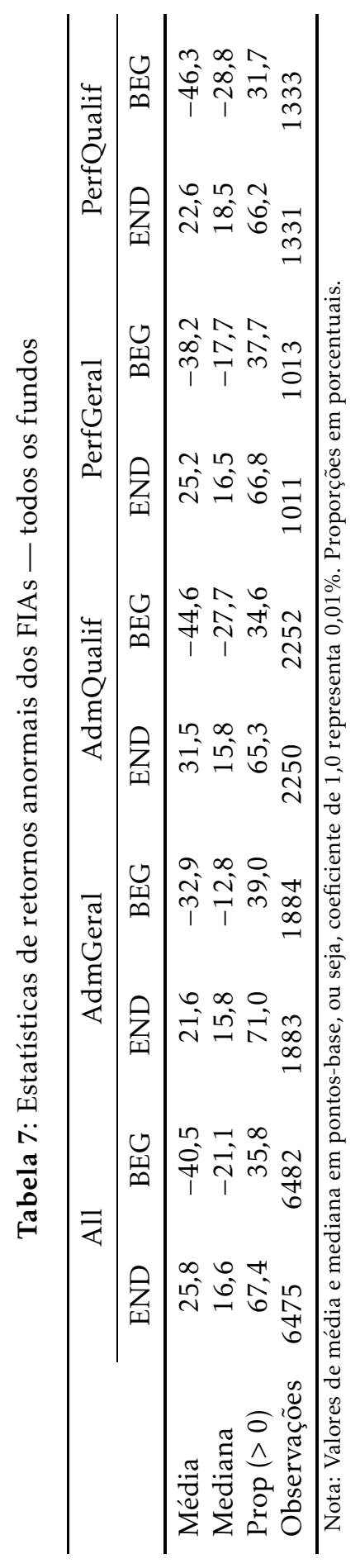


tam manipular o valor da cota de seus fundos, seja para reportarem melhores desempenhos, seja para obter uma maior remuneração por meio da taxa de performance, atuar de modo a elevar o preço de fechamento das ações, especialmente as menos líquidas.

Para estimar o efeito da mudança do preço médio pela cotação de fechamento, foi criada a variável binária close que assume o valor zero para o período em que era adotado o preço médio na marcação dos fundos e assume valor um quando a marcação a mercado dos ativos passou a ser determinada pelo preço de fechamento.

\section{Carteiras dos FIAs}

Os modelos são semelhantes aos da Seção 4.1, mas um termo com a interação entre a nova variável close e as variáveis de encerramento de período consideradas em cada um dos respectivos modelos e outro termo com a interação entre a variável close e as variáveis de início de período foram considerados em cada um dos respectivos modelos. A Equação 5 representa o modelo em que são analisados os efeitos de encerramento e início de período, sem fazer distinção entre os finais e inícios de primeiro semestre, do segundo semestre e dos outros meses do ano. A Equação 6 representa o modelo em que são considerados apenas os finais e inícios do primeiro e segundo semestres, sem fazer distinção entre eles. O modelo em que é feita a distinção entre o primeiro e segundo semestres, bem como são incluídos os outros meses do ano, é representado pela Equação 7 .

$$
\begin{aligned}
& z_{i, t}=\beta_{i, 0}+\beta_{i, 1} E N D_{t}+\beta_{i, 2} B E G_{t}+\beta_{i, 3} \text { close }_{t} . E N D_{t}+ \\
& \beta_{i, 4} \text { close }_{t} . B E G_{t}+\varepsilon_{4 i, t} \\
& z_{i, t}=\beta_{i, 0}+\beta_{i, 1} S E N D_{t}+\beta_{i, 2} S B E G_{t}+\beta_{i, 3} \text { close }_{t} . S \text { SND }_{t}+ \\
& \beta_{i, 4} \text { close }_{t} . S B E G_{t}+\varepsilon_{5 i, t} \\
& z_{i, t}=\beta_{i, 0}+\beta_{i, 1} S 1 E N D_{t}+\beta_{i, 2} S 2 E N D_{t}+\beta_{i, 3} S 1 B E G_{t}+ \\
& \beta_{i, 4} S 2 B E G_{t}+\beta_{i, 5} M E N D_{t}+\beta_{i, 6} E N D_{t}+\beta_{i, 7} \text { close }_{t} . E N D_{t}+ \\
& \beta_{i, 8} \text { close }_{t} . B E G_{t}+\varepsilon_{6 i, t}
\end{aligned}
$$

Na Tabela 8, são apresentados os resultados para os modelos computados pelas Equações 5 e 7, para manter a parcimônia. Os resultados para o modelo da Equação 6 não divergem muito dos resultados encontrados nos modelos apresentados na Tabela 8.

A inclusão da interação das variáveis fez com que alguns coeficientes deixassem de ser estatisticamente significantes e em alguns casos o coeficiente passou a ter o sinal diferente do esperado, mas estatisticamente não significante. Ponderado pelo PL dos fundos, a carteira de fundos que apresentou o maior número de coeficientes estatisticamente significantes foi a dos FIAs em que há cobrança da taxa de performance destinados ao público geral (PerfGeral).

O coeficiente da interação entre a variável close e as variáveis de encerramento (início) de período apresenta o sinal positivo (negativo) em todas as 


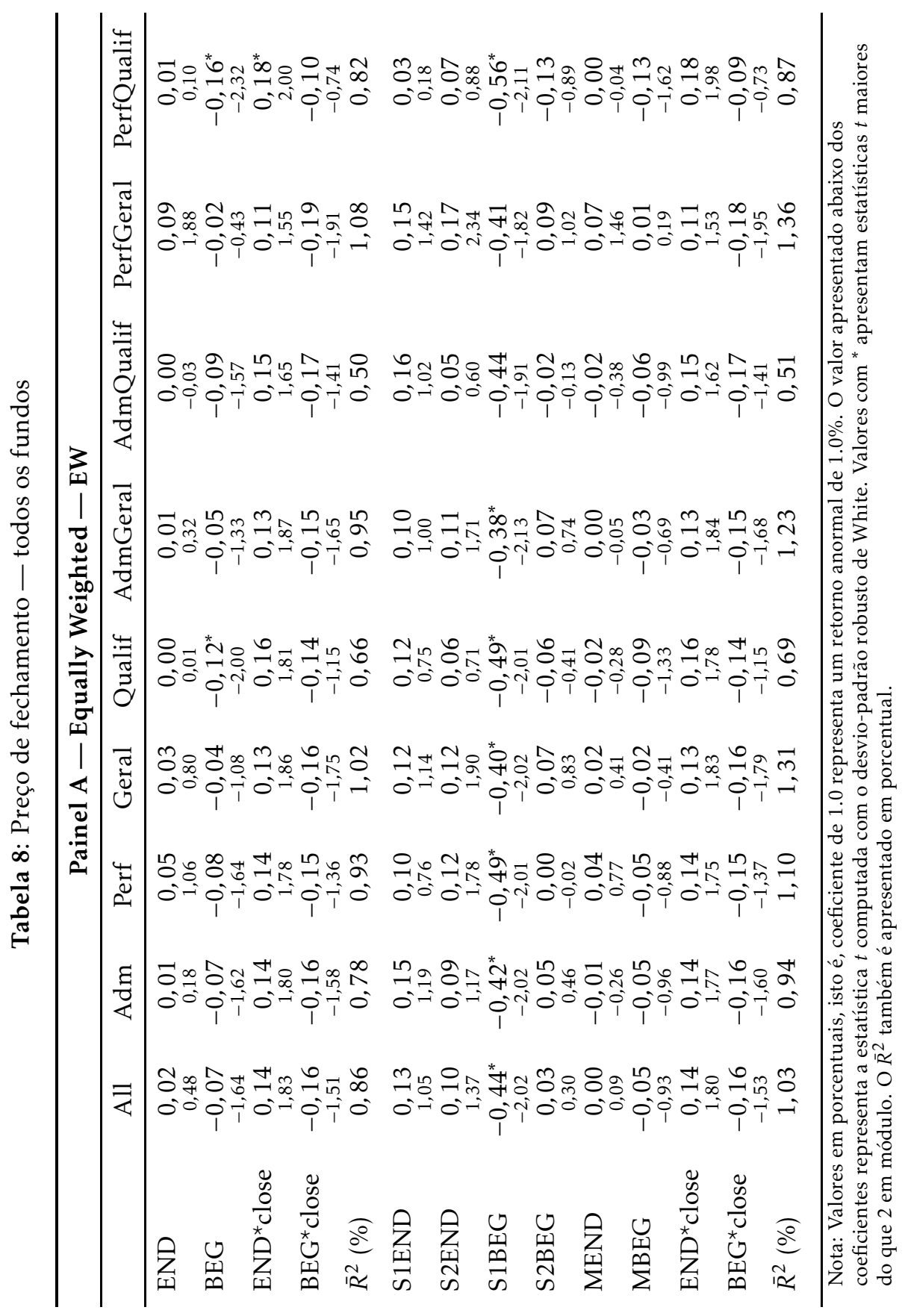




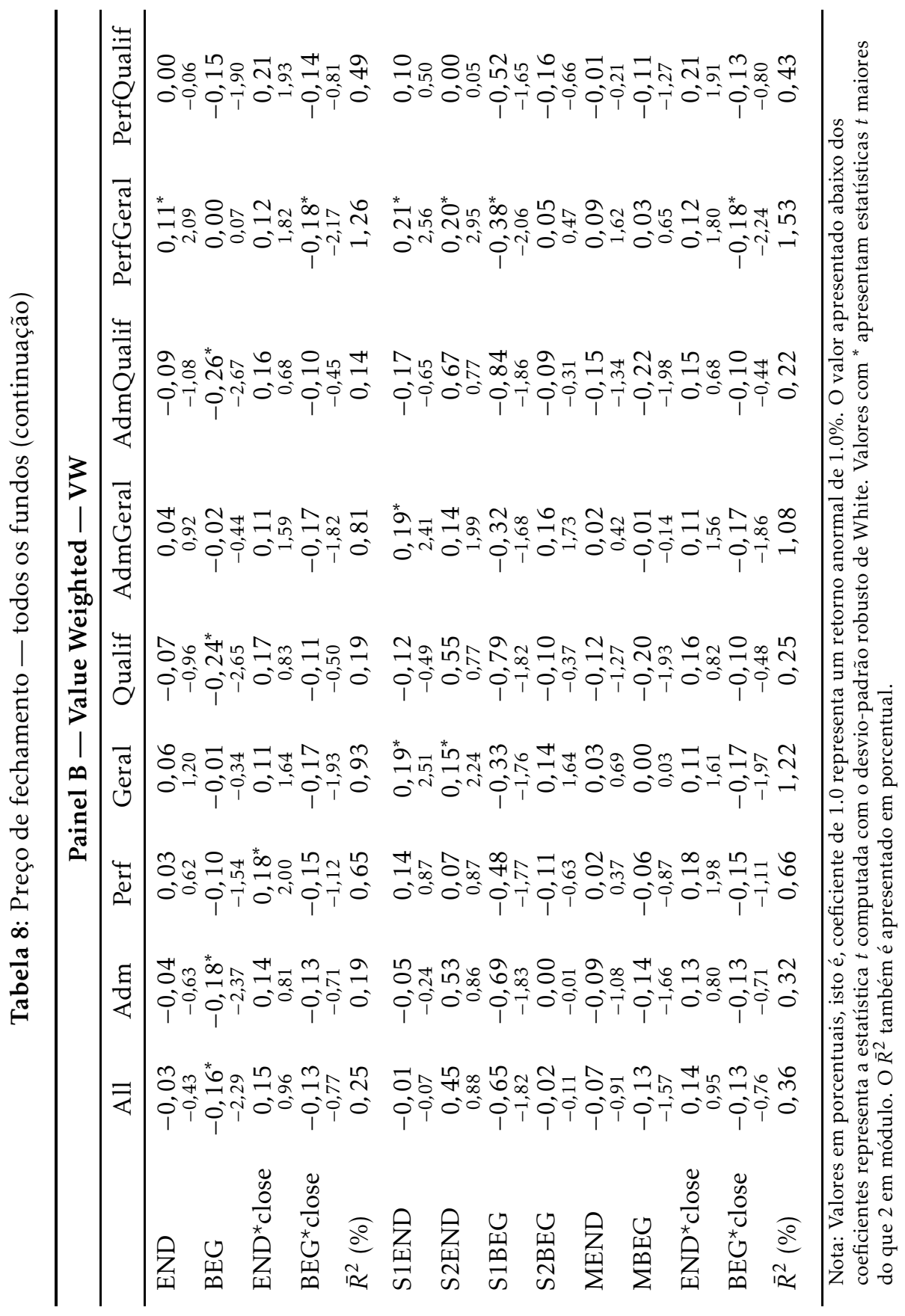


especificações, sendo consistente com a hipótese de que o problema dos retornos anormais positivos (negativos) no último (primeiro) dia dos semestres se tornou maior em termos absolutos do que era quando a marcação a mercado adotava o preço médio ponderado pelo volume de negócios. Entretanto, a maior parte desses resultados apresenta estatística $t$ com valor absoluto entre 1,5 e 2 , e poucos casos apresentam estatísticas $t$ superiores a 2.

Dessa forma, os resultados encontrados representam apenas indícios fracos de que a adoção do preço de fechamento como critério para a marcação a mercado dos fundos pode ter aumentado o problema dos retornos anormais positivos no último dia do semestre, acompanhados de retornos anormais negativo no dia seguinte.

\section{Proporção de retornos anormais positivos}

A Tabela 9 apresenta os resultados para a substituição do retorno anormal das carteiras dos fundos nas Equações 5 a 7 pela proporção de fundos em que o retorno anormal é positivo.

A maior parte dos coeficientes apresenta o sinal esperado, mas diminui o número de casos em que são estatisticamente significantes, quando comparados aos modelos da Tabela 6 . Os coeficientes da interação entre a variável close e as outras variáveis apresentaram o sinal consistente com o aumento da proporção de fundos que recorrem à inflação do valor da cota no encerramento do período, seguido da reversão no dia seguinte, mas na maior parte dos casos o coeficiente não apresenta significância estatística.

Os modelos dos fundos destinados aos investidores qualificados, fazendo a distinção ou não para a cobrança da taxa de performance, apresentam coeficientes positivos e estatisticamente significantes para a interação entre a variável close e a variável de encerramento de período, o que indica que aumentou a proporção de retornos anormais positivos nos encerramentos de mês e de semestre após a adoção do preço de fechamento como critério de marcação a mercado.

Mesmo que o coeficiente da interação entre a variável close e variável de encerramento de período tenha apresentado significância estatística somente no caso dos fundos destinados a investidores qualificados, a maior ocorrência de coeficientes estatisticamente significantes está no caso dos fundos voltados ao público geral, especialmente quando estão agrupados os fundos que cobram ou não taxa de performance (Geral).

Os resultados dos modelos que empregam a proporção de retornos anormais positivos representam novos indícios de que pode haver um problema de agência na gestão dos FIAs, e esse problema pode ter se acentuado após a adoção do preço de fechamento como critério de marcação a mercado em detrimento do preço médio. Esse problema de agência está mais evidente nos fundos voltados ao público geral, mas a adoção do preço de fechamento elevou a proporção de fundos destinados a investidores qualificados que passaram a apresentar retornos anormais positivos no último dia dos meses e dos semestres.

\section{Análise individual dos FIAs}

A Tabela 10 apresenta as estatísticas dos retornos anormais dos fundos analisados individualmente, de maneira semelhante ao feito na Tabela 7, na Seção 


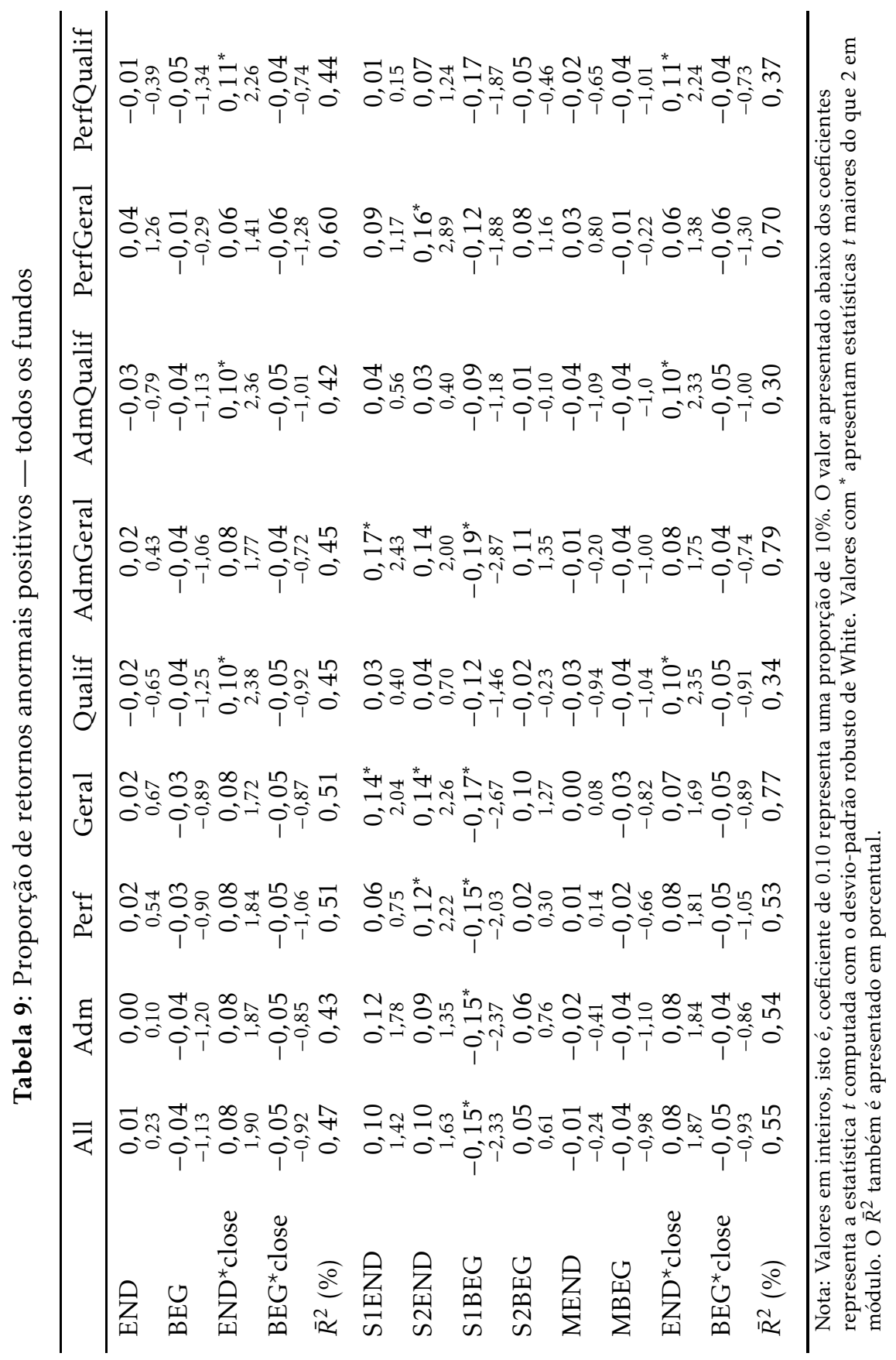




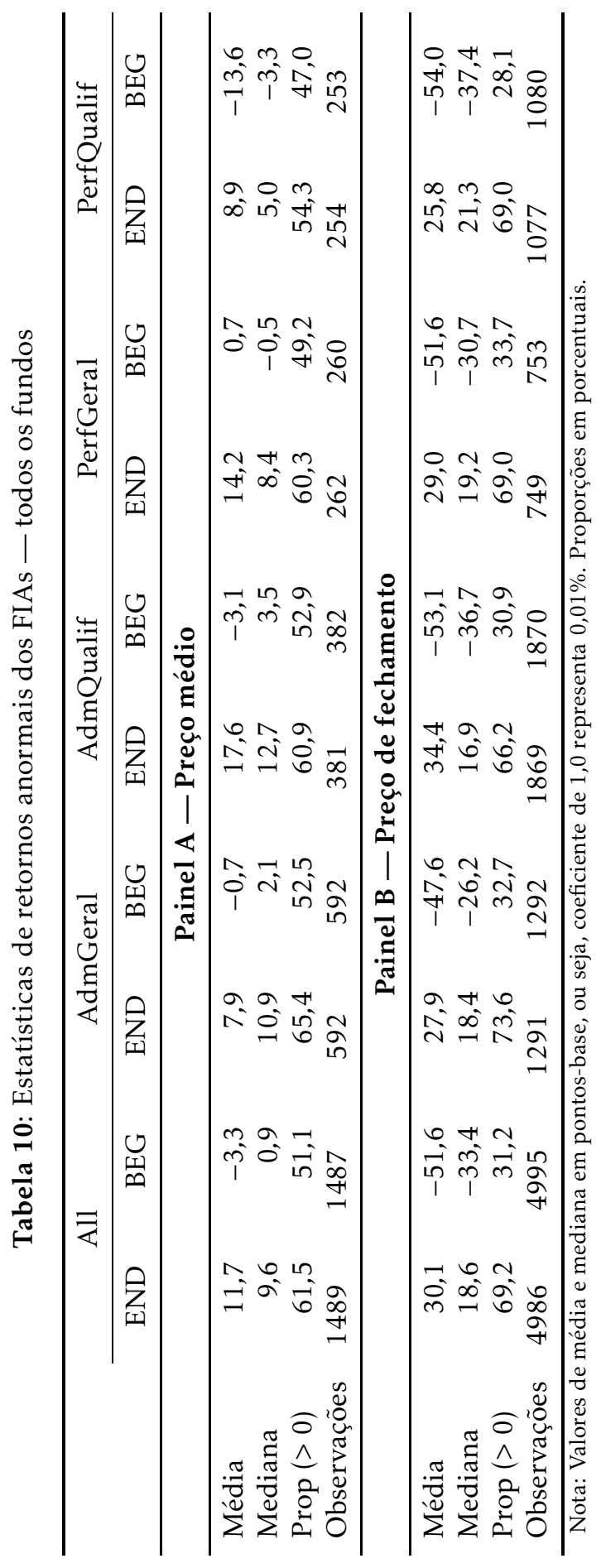


4.1, mas agora separando entre os períodos em que a marcação a mercado era feita por meio do preço médio (Painel A) e o período em que a marcação a mercado adota o preço de fechamento (Painel B). Em todos os casos, os valores das médias e medianas do retorno anormal apresentaram valores absolutos maiores nos dias de encerramento $(E N D)$ e no dia seguinte $(B E G)$ após a adoção do preço de fechamento como critério para a marcação a mercado dos FIAs.

A proporção de retornos positivos no encerramento (dia seguinte) dos períodos de apuração também aumentou (diminuiu) em todos os casos após a adoção do preço de fechamento, o que pode indicar que essa mudança propiciou a disseminação da prática de inflacionar o valor das cotas no encerramento do período, indicando possíveis problemas de agência na gestão dos FIAs.

Cabe destacar ainda que a reversão dessa inflação no valor da cota, representado pelo retorno anormal negativo no dia seguinte ao encerramento do período apresenta um valor absoluto maior do que a respectiva inflação no valor da cota. Essa reversão em maior magnitude do que a inflação indica que o ônus de buscar registrar um desempenho mais alto por parte do gestor é pago pelo investidor por meio de um retorno anormalmente baixo no dia seguinte, em que devem ser revertidas as operações que propiciaram a inflação do valor da cota. No período em que a marcação a mercado adotava o preço médio, em alguns casos o retorno anormal no dia seguinte ao encerramento apresentava o sinal positivo para a média ou mediana, ainda que muito próximos de zero.

\section{Conclusões}

Os resultados encontrados indicam que os FIAs não estão imunes a problemas de agência, mas esses problemas podem ser atenuados quando os investidores do fundo têm uma maior capacidade de monitorar o comportamento do gestor de seus recursos. Investidores qualificados conseguem, em princípio, acompanhar melhor a atuação do gestor do que o público geral. Os resultados encontrados nesta pesquisa são consistentes com esse princípio.

A presença da taxa de performance em alguns fundos poderia criar incentivos para os gestores desses fundos buscarem inflacionar o valor da cota com o intuito de obterem uma maior remuneração. A análise que considera a distinção entre fundos que cobram ou não taxa de performance não gerou evidências tão claras de desvios de conduta por parte do gestor como a separação entre o tipo de clientela a que o fundo é destinado.

Ao serem construídas as carteiras dos FIAs, tem-se que os fundos destinados aos investidores qualificados apresentam melhores desempenhos do que os voltados ao público geral, seja quando consideramos todos os fundos da amostra, seja quando são escolhidos apenas os fundos em funcionamento desde o início da amostra. Cabe mencionar que os valores encontrados para as carteiras de fundos apresentam retornos superiores aos registrados pelos índices de referência, um indicativo de possíveis problemas de viés de sobrevivência, uma vez que na amostra utilizada não foi possível utilizar os dados de fundos descontinuados. Os resultados usualmente encontrados na literatura são de que os fundos mútuos não são capazes de, na média, superarem os índices de referência.

A análise da proporção de retornos anormais indica que a prática de buscar inflacionar o valor da cota no encerramento dos semestres está dissemi- 
nada nos fundos existentes. Nos fundos voltados ao público geral a prática está mais disseminada do que nos fundos voltados aos investidores qualificados. Os resultados para a distinção entre fundos que cobram ou não taxa de performance não geram evidências tão claras quanto a separação por tipo de clientela, de forma que o problema de agência pode estar associado ao tipo de clientela e não à tentativa de simplesmente obter maiores taxas de performance.

Desse modo, a aplicação de uma regra mais restritiva para a incidência da taxa de performance em fundos voltados ao público geral pode ser benéfica aos investidores, uma vez que diminui as oportunidades dos gestores obterem uma maior remuneração por meio da inflação do valor da cota do fundo nos encerramentos de período.

A adoção do preço de fechamento em detrimento do preço médio como critério de marcação a mercado dos fundos, por sua vez, pode ter acentuado o problema da inflação dos valores das cotas nos encerramentos de período, mas as evidências encontradas ainda são fracas. Tanto a magnitude média quanto a proporção de fundos em que os retornos anormais ocorrem passaram a ser maiores após a adoção do novo critério, o que pode ter agravado o problema de agência nos FIAs. Os fundos voltados ao público geral continuam mais propensos a apresentarem problemas de agência do que os voltados a investidores qualificados.

Os resultados da pesquisa têm como limitação o uso de dados de fundos em funcionamento no momento da coleta dos dados (viés de sobrevivência), ainda que representem uma parcela significativa da indústria de fundos de investimento em ações do Brasil. As informações gentilmente disponibilizadas pela Quantum ${ }^{\circledR}$ referentes aos fundos descontinuados não puderam ser incluídas na pesquisa por não permitirem a análise dos retornos diários, bem como a especificação dos contratos de remuneração do gestor ou ao tipo de clientela a que o fundo é destinado.

Outra limitação do trabalho é não examinar as carteiras diárias nas datas próximas ao encerramento dos períodos. Apenas a carteira do último dia do mês é disponibilizada pela CVM e pela Quantum ${ }^{\circledR}$. Com as carteiras diárias, seria possível ver se as alterações tinham como objetivo inflacionar a cota do fundo temporariamente ou se era uma modificação em benefício dos cotistas daquele fundo.

Nessa pesquisa não são examinados os dados para as ações nos últimos dias dos períodos e nos dias subsequentes, tais como preço, volume negociado e quantidade de negócios, entre outros. A análise desses dados pode constituir um futuro caminho a ser explorado com o objetivo de compreender o motivo para a existência de retornos anormais nas cotas dos fundos nos encerramentos dos períodos.

\section{Agradecimentos}

O presente trabalho foi realizado com apoio do CNPq, Conselho Nacional de Desenvolvimento Científico e Tecnológico - Brasil.

O autor agradece à Quantum ${ }^{\circledR}$ pela disponibilização dos dados para esse trabalho e às sugestões do Prof. Ricardo Pereira Câmara Leal, de Gyorgy Varga, de Maxim Wengert e do parecerista anônimo. 


\section{Referências Bibliográficas}

Brown, K. C., Harlow, W. V. \& Starks, L. T. (1996), 'Of tournaments and temptations: An analysis of managerial incentives in the mutual fund industry', Journal of Finance 51(1), 85-110.

Carhart, M. M. (1997), 'On persistence in mutual fund performance', Journal of Finance 52(1), 57-82.

Carhart, M. M., Kaniel, R., Musto, D. K. \& Reed, A. V. (2002), 'Leaning for the tape: Evidence of gaming behavior in equity mutual funds', Journal of Finance 57(2), 661-693.

Comerton-Forde, C. \& Putnins, T. J. (2011), 'Measuring closing price manipulation', Journal of Financial Intermediation 20(2), 135-158.

Gallagher, D. R., Gardner, P. \& Swan, P. L. (2009), 'Portfolio pumping: An examination of investment manager quarter-end trading and impact on performance', Pacific-Basin Finance Journal 17(1), 1-27.

Grinblatt, M. \& Titman, S. (1989), 'Adverse risk incentives and the design of performance-based contracts', Management Science 35(7), 807-822.

Huang, J., Sialm, C. \& Zhang, H. J. (2011), 'Risk shifting and mutual fund performance', Review of Financial Studies 24(8), 2575-2616.

Warner, J. B. \& Wu, J. S. (2011), 'Why do mutual fund advisory contracts change? performance, growth, and spillover effects', Journal of Finance 66(1), 271-306. 